\title{
PRECISION FLOW CONTROL COMPONENTS SUPPORTING THE EVOLUTION OF SPACECRAFT PROPULISON SYSTEMS
}

\author{
David Hodge \\ Moog Space and Defense Group \\ Nisseki Yokohama Bldg. 14F \\ 1-1-8 Sakuragi-cho, Naka-ku, Yokohama, 231-0062 Japan \\ (E-mail: dhodge@moog.com)
}

\begin{abstract}
A number of design and manufacturing techniques have been established over the years to ensure reliable products for spacecraft fluid control. Designs and processes originally intended for spacecraft chemical propulsion now have applications in electric propulsion as well as missile defense. The common element in each application is manufacturing processes that ensure assembly cleanliness, reliability, and repeatability.
\end{abstract}

\section{KEY WORDS}

Space, Propulsion, Contamination, Quality

\section{INTRODUCTION}

Moog is widely known for its contributions to the hydraulic fluid flow and pressure control field. Originally developed by Bill Moog 1951 to provide steering control for missiles, the design and core manufacturing techniques of the electro-hydraulic servovalve quickly spread to support aircraft and industrial automation applications.

A less obvious derivative of the hydraulic servovalve emerged in the 1980's as the need to reliably meter and seal propellants for orbiting spacecraft became apparent. The electro-magnetic circuit of torque motor thruster valves and latching valves are similar to those used in the first stage electro-hydraulic servovalves. However, precise flow control of gas in the vacuum environment of space required increased care in the preparation of sealing surfaces, cleaning parts of burrs and oils, creating assemblies without threaded fasteners, and handling assemblies in such as way as to avoid introduction of potential contaminants.

\section{Enabling Technologies for Space Valves}

One of the most critical, and often overlooked, elements to successful production of critical flow control components for space application is the rigorous application of component cleaning and careful handling. Contaminant as small as 5 micron can adversely affect the hardware and cause failure of mission critical subsystems. A comprehensive contamination control program includes a Class 1000 clean air environment, filtering of test fluids used on flight hardware, control of manufacturing processes to minimize the generation of contaminant, and a periodic inspection process to ensure compliance.

With the support of JAXA, Moog recently introduced this type of facility and process in Hiratsuka, Japan. The $59 \mathrm{~m}^{2}$ clean room was designed and tested to conform to the requirements of JIS B9919 (ISO14644-4). In addition, a water flushing stand was designed and installed utilizing filtered de-ionized water and pressurized gaseous nitrogen. The resulting 
turbulent flow effectively scrubs the flow paths of the unit, eliminating potential contaminant.

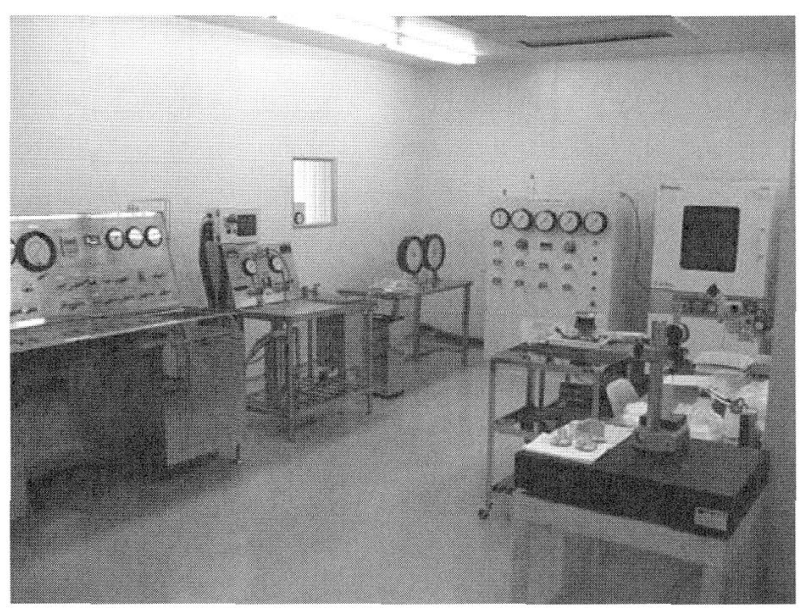

Figure 1 -- Clean Room for Space Valve Manufacturing in Hiratsuka, Japan

While a valve can be built without internal contaminants, traditional solenoid type valves have a potential to generate contamination over the spacecraft mission life due to sliding friction between the moving parts.

Moog's patented suspended armature solenoid valve eliminates this sliding fit by using a proprietary designed S-spring, shown below in both the valve open and closed positions.
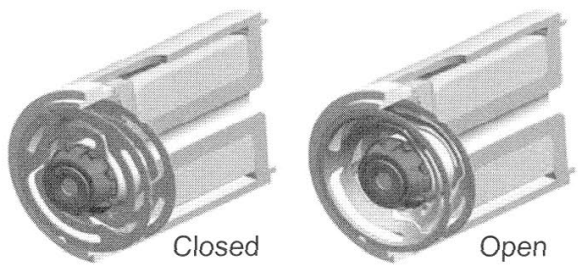

Figure 2 - Suspended Armature Valve Design

As shown in Figure 3, tests conducted at Moog's engineering facilities in East Aurora, New York demonstrate a substantial reduction in particulate generated by valves using this design feature when compared to conventional sliding fit solenoid valves.

The spring is designed for infinite fatigue life, which has been supported by multiple tests including a $2,000,000$ cycle test. The manufacture of the critical spring assembly is accomplished in a 10 -step process, including:

- Precipitation Hardening
- Chemical Etching

- Lapping

- Electrochemical Polish

- In-Process Inspections

Each of these steps is performed to proprietary process control documents in accordance with an AS9100 Quality Control Plan. The establishment and qualification of these processes for a particular configuration valve enables parametric applications for a wide variety of high reliability, contamination free flow control needs.

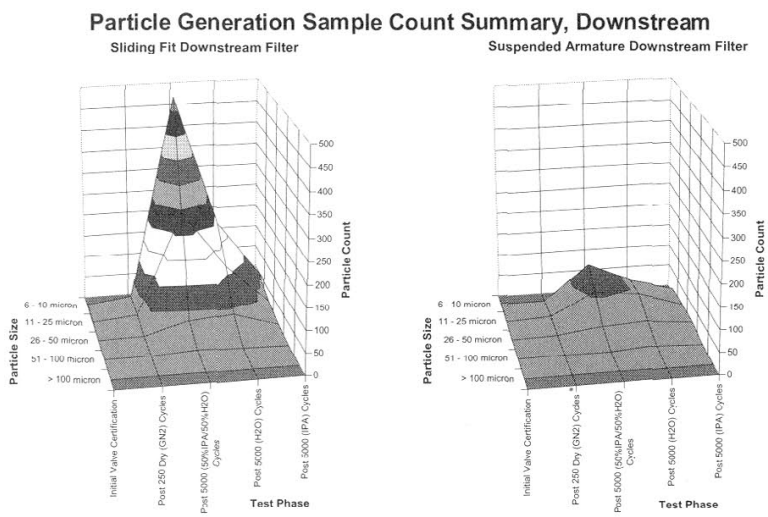

Figure 3 - Reduction in Generated Contaminant

Finally, the components and subassemblies of the propulsion valve are mechanically joined by electron beam welding. This process is typically used for spacecraft propulsion systems for the following reasons:

- Minimum weight for the mechanical joint

- No contamination is generated during joining (as compared to threaded fasteners, for instance)

- Leak proof sealing to $2000 \mathrm{psi}$ and beyond

- No deterioration in space environment (temperature extremes and radiation)

Electron beam processes have been commercially available for decades, and can be applied if sufficient care is taken in process control. These processes are again controlled by quality control documentation and require a combination of non-destructive inspection as well as destructive sampling of weld coupons with each batch.

\section{Potential Applications}

The solenoid valve produced by Moog Japan demonstrates all of the necessary design and manufacturing elements to support various applications. The typical performance parameters of the $20 \mathrm{~N}$ valve are shown in Table 1 below ${ }^{4}$. 
Table 1 - Typical Performance of 20N Thruster Valve

\begin{tabular}{l|c}
\hline Property & Target value \\
\hline Compatible fluid & $\begin{array}{c}\mathrm{N}_{2} \mathrm{H}_{4}, \mathrm{IPA}, \mathrm{GN}_{2}, \mathrm{GHe}, \\
(\mathrm{NTO} / \mathrm{MON}-3)\end{array}$ \\
\hline Pressure & 0 to $2.76 \mathrm{MPa}$ \\
\hline operating & $\mathrm{MEOP} \times 1.5$ \\
\hline proof & $\mathrm{MEOP} \times 2.5$ \\
\hline burst & 10 gram/sec $@ \mathrm{~N}_{2} \mathrm{H}_{4}$ \\
\hline Flow rate & $0.172 \mathrm{MPa}(\mathrm{d})$ \\
\hline Pressure drop & $<1 \times 10^{-5} \mathrm{scc} / \mathrm{sec}$ \\
\hline Internal leakage & 24 to $32 \mathrm{VDC}$ \\
\hline Operating voltage & $\begin{array}{c}\text { Open: }<15 \mathrm{msec} @ \mathrm{MEOP} \\
\text { Close: }<10 \mathrm{msec} @ \mathrm{MEOP}\end{array}$ \\
\hline Response time & $<30 \mathrm{~W} @ 28 \mathrm{~V} / 5^{\circ} \mathrm{C}$ \\
\hline Power consumption & Wet: $1,000,000 \mathrm{cycle}$ \\
\hline Cycle life & $50,000 \mathrm{cycle}$ \\
\hline Mechanical environment & Dry: \\
\hline Random vibration & $42 \mathrm{Grms}$ \\
\hline Shock & $2,800 \mathrm{G}$ \\
\hline Temperature range & 5 to $149{ }^{\circ} \mathrm{C}$ \\
\hline Weight & $<300$ gram \\
\hline
\end{tabular}

More importantly, the processes are documented, controlled, and scaleable to support a large variety of isolation valves for propulsion systems ranging in thrust from less than $1 \mathrm{~N}$ to over $500 \mathrm{~N}$ with only parametric modifications. The design can also cvolve to support bipropellant applications with a simple change in seal material to ensure fluid compatibility.

Applications also exist beyond conventional monopropellant and bipropellant flow and isolation.

Minor design features can be added and simple changes made to parts in order to create proportionality within the valve. Thus, changes in flow rate would be initiated by changing the applied current to the coil. In one example, the valve remains in the closed position with input currents between 0 and $\sim 90 \mathrm{~mA}$, then starts to modulate flow between $90 \mathrm{~mA}$ and a maximum applied current of $125 \mathrm{~mA}$. The $90 \mathrm{~mA}$ starting current may vary slightly from valve to valve due to build tolerances within the solenoid valve. This variation can be accommodated for within the control system.

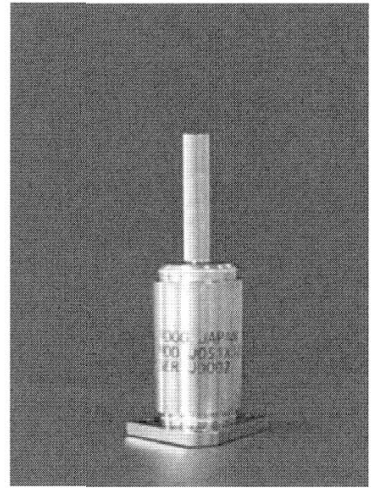

Figure 4 - Propulsion Valve Manufactured in Japan

The proportional valve, when driven by a Proportional, Integral, Derivative (PID) controller, results in a proportional flow or pressure control subsystem. These subsystems have been demonstrated to provide throttling control for Ion propulsion systems, providing significantly increased efficiency for spacecraft propulsion $^{2}$.

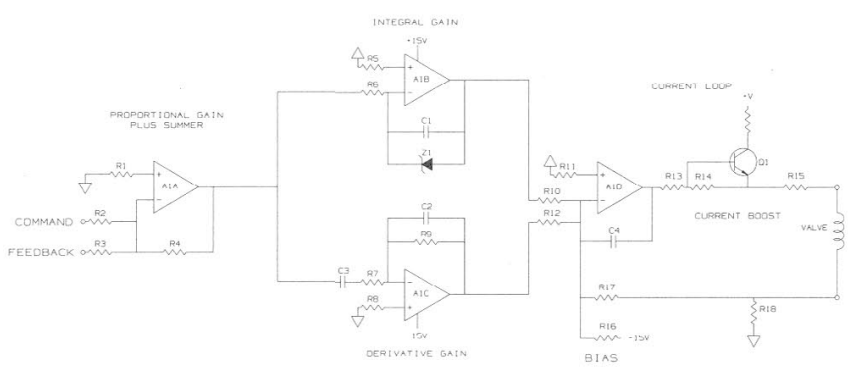

Figure 5 - Typical PID Controller

Finally, the need for highly reliable, extreme environment capable valves is not limited to orbiting spacecraft. Similar propulsion valves are used in reaction control assemblies for launch vehicles. This technology has also recently been coupled with high speed computing in complex Divert and Attitude Control Systems (DACS). This systems support the national defense against intercontinental ballistic missiles by dynamically colliding with incoming weapons at extremely high speeds. The flow valves in the divert and attitude control thrusters are manufactured using similar or identical processes to the space propulsion valves discussed above. 


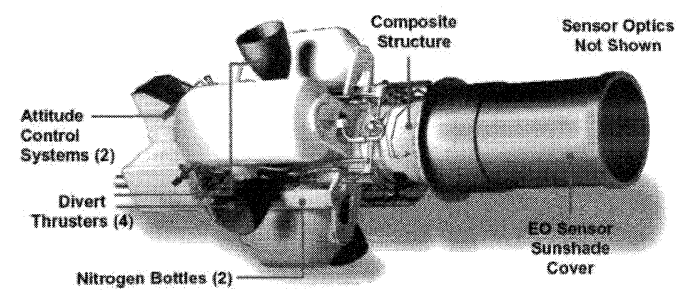

Figure 5 - Missile Defense

Divert and Attitude Control System

\section{Conclusions}

Moog has been a world leader in flow control for over five decades. Technology derivatives of the electro-hydraulic servovalve have led to flow control applications of a variety of spacecraft propellants. Careful process control is essential to the success of space missions, as there is no opportunity to repair or replace such components once on orbit. This level of process control supports growth to future applications, including advanced ion propulsion for spacecraft, as well as critical defense applications such as ballistic missile intercept. Moog has established and qualified these critical processes in facilities both in the United States as well as in Japan.

\section{REFERENCES}

1. Bushway III, E. and King P.T. et al, "A Xenon Flowrate Controller for Hall Current Thruster Applications" IEPC-01-315, October, 2001.

2. Bushway III, E. and Perini, "Proportional Flow Control Valve (PFCV) for Electric Propulsion Systems" AIAA-2000-3551, July, 2000.

3. Huftalen, Richard L, "Next Generation Propellant Isolation Valve Design and Development" AIAA, July 2006.

4. Kushiki, Kenichi and Kagiwara, Kenichi and Sugimura et al, "Development of a $20 \mathrm{~N}$ Thuster Valve for Spacecraft Propulsion System" On-Board Energetic Equipment, 2004. 